\title{
ENTRE AS ESCOLAS “DE OUTRO TEMPO”, "DE AGORA” E O “TRABALHO”: OS SENTIDOS DAS PERMANÊNCIAS DE ESTUDANTES NA EJA DA ZONA RURAL DO CEARÁ 95
}

\author{
BETWEEN SCHOOLS OF ANOTHER TIME, TODAY'S SCHOOLS AND THE \\ WORK: THE SENSES OF STUDENTS 'PERMANENCES IN THE AREA OF THE \\ CEARÁ RURAL AREA
}

\author{
Francisco Josimar Ricardo Xavier ${ }^{96}$ \\ Adriano Vargas Freitas ${ }^{97}$
}

\begin{abstract}
Resumo
Este artigo objetiva apresentar os sentidos das permanências de estudantes na EJA. Como instrumento de coleta de dados, utilizamos entrevistas semiestruturadas, realizadas com jovens e adultos de uma escola municipal da zona rural do Ceará. Os materiais coletados foram analisados por meio da técnica de Análise Textual Discursiva. Os resultados mostram que os estudantes trazem lembranças de uma escola de outro tempo e entendem a escola de agora como um espaço melhor para aprender os saberes escolares. A busca por estes saberes, somados à conquista de um trabalho melhor e aos laços de afetividade, construídos pelos estudantes em sala de aula, influenciam sobre os sentidos de suas permanências na EJA.
\end{abstract}

Palavras-chave: Educação de jovens e adultos. Permanência. Escola da zona rural

\begin{abstract}
This article presents the meanings of students' stays in youth and adult education. We used, as an instrument of data collection, semi-structured interviews with young people and adults from a municipal school in the rural area of Ceará. The collected materials were analyzed through the Discursive Textual Analysis technique. The results show that students bring back memories of an "old-school" school. They understand today's school as a better place to learn school knowledge. The search for knowledge, the achievement of a better job, and ties of affectivity built by the students in the classroom, are the influence son the permanence of these students in the EJA.
\end{abstract}

Keywords: Youth and adult education. Permanence. Rural school.

\footnotetext{
${ }^{95}$ Este artigo traz alguns resultados da pesquisa de Mestrado em Educação intitulada "As influências de práticas pedagógicas matemáticas na EJA sobre a permanência de estudantes da zona rural de Sobral", defendida na Faculdade de Educação da Universidade Federal Fluminense, em 2019.

${ }^{96}$ Mestre em Educação pela Universidade Federal Fluminense, UFF. Tem interesse em pesquisas nas áreas: Educação, Educação Matemática, Etnomatemática, Currículo e Práticas Pedagógicas na modalidade Educação de Jovens e Adultos, EJA. Integra o Grupo de Pesquisa em Educação Matemática (GRUPEMAT), do Instituto de Educação de Angra dos Reis IEAR/UFF e o Grupo de Etnomatemática da UFF (GETUFF). E-mail: josimar_xavier@id.uff.br

${ }^{97}$ Doutor em Educação Matemática pela Pontifícia Universidade Católica de São Paulo, Mestre em Educação pela Universidade Católica de Petrópolis, Especialista em Ensino de Matemática pela Universidade Federal do Rio de Janeiro e Graduado em Matemática. Professor do Programa de Pós Graduação em Educação da UFF. Professor do Instituto de Educação de Angra dos Reis. Desenvolve pesquisas relacionadas à Educação Matemática, Formação de Professores e Currículos direcionados a Educação de Jovens e Adultos. E-mail: adrianovargas@id.uff.br
} 


\section{RevistAleph}

\section{Introdução}

Este artigo apresenta resultados de uma pesquisa de Mestrado em Educação que versa sobre a temática permanência na Educação de Jovens e Adultos (EJA). A razão para discutir a referida temática partiu da experiência de um dos autores como professor de jovens e adultos em uma escola da zona rural. Nesta escola, o mesmo percebeu haver um grupo de estudantes que era bastante presente nas aulas, em detrimento de falas de alguns professores, por sinal, os mais experientes na EJA, que relatavam a pouca frequência dos estudantes e que havia bastante evasão.

A definição do estudo com foco na permanência foi endossada quando em nossas leituras e aprofundamentos de aportes teóricos, percebemos haver uma vasta literatura de pesquisas que ainda buscam explicar os fenômenos da evasão e do fracasso escolar, (OLIVEIRA, 1999) em contrapartida de se compreender os motivos de os jovens e adultos estarem na escola. Carmo e Carmo (2014) nos possibilitam afirmar esta nossa percepção quando, em seu estudo sobre como o sentido de permanência tem sido apresentado em teses e dissertações, nos informam que entre os anos de 1996 a 2012, foram publicados apenas 44 trabalhos envolvendo a temática permanência ou semelhante. Destes, 31 apresentam a EJA como foco e foram publicados a partir do ano de 2007. Outro ponto que destacamos destas publicações referidas por Carmo e Carmo (2014), é o fato de elas concentrarem-se nas Regiões Sul e Sudeste do país.

Compreendemos que estas pesquisas analisadas se empregam dentro de um contexto e determinado período de tempo. Contanto, consideramos ser possível que muitos desses autores/pesquisadores ainda estão produzindo a partir destas mesmas localizações e instituições constatados por Carmo e Carmo (2014), o que nos serviria para reafirmar a significativa limitação geográfica de boa parte das pesquisas atuais.

Desta maneira, quando trazemos uma escola do Ceará como lócus de nossa pesquisa, entendemos que dentre as suas contribuições e relevância para o campo da Educação, está o fato de incluirmos a Região Nordeste nas discussões sobre permanência na EJA. Ao trazermos os estudantes como sujeitos pesquisados, compreendemos que suas falas podem suscitar reflexões sobre as práticas dos professores, as políticas educacionais volta à EJA e suas perspectivas sobre a escola de jovens e adultos. 


\section{RevistAleph}

Nos limites deste artigo, objetivamos apresentar os sentidos das permanências de estudantes na EJA da zona rural do Ceará. Nossas discussões envolvem analisar os fatores que levam os jovens e adultos estarem na EJA, bem como, suas compreensões sobre a escola da zona rural.

Optamos por elaborar o artigo em duas seções: uma primeira, em que apresentamos o percurso da pesquisa, onde destacamos os tópicos relativos à metodologia empregada, ao espaço lócus da pesquisa e os perfis dos sujeitos pesquisados; e uma segunda, na qual trazemos os tópicos que compõem os resultados da pesquisa e as discussões. Por fim, apresentamos nossas Considerações finais.

\section{Percurso da pesquisa}

Nesta seção apresentamos o percurso trilhado em nossa pesquisa. Optamos por trazer, primeiramente, a metodologia empregada, em que destacamos os instrumentos de coleta de dados e a técnica de análise utilizada. Procurando situar o leitor onde ocorreu nosso campo, trazemos um tópico no qual caracterizamos a escola espaço lócus da pesquisa.

Finalizamos esta seção, apresentando o perfil da turma de EJA pesquisada e dos estudantes entrevistados.

\section{Metodologia empregada}

Em uma leitura ampla, entendemos que nosso estudo se trata de uma pesquisa qualitativa. Entendemos como qualitativa, na medida em que, dispondo do contato direto com as fontes de informações, priorizamos as riquezas de detalhes das falas dos sujeitos pesquisados (CHIZZOTTI, 2013), em detrimento de alguns dados quantitativos também coletados.

Para fins de uma melhor construção da pesquisa, utilizamos entrevistas como instrumentos de coleta de dados, tendo como referência os estudos de Gil (2008). Segundo o referido autor, podemos entender entrevista como uma "técnica em que o investigador se apresenta frente ao investigado e Ihe formula perguntas, com o objetivo de obter dados que interessam à investigação" (GIL, 2008, p. 109). 


\section{RevistAleph}

No intuito de obtermos as respostas de maneira mais clara e objetiva possível, definimos utilizar as entrevistas do tipo semiestruturada que, de acordo com Lüdke e André (2007), seguem um roteiro ou esquema básico de perguntas, de maneira a facilitar o desenvolvimento da mesma e, posteriormente, a análise do pesquisador. Complementam tais autoras que, mesmo partindo de um esquema previamente elaborado, quando da entrevista semiestruturada, é permitido ao pesquisador fazer as necessárias adaptações no intuito de focar o entrevistado no que foi perguntado.

Os materiais das entrevistas semiestruturadas foram analisados à luz da técnica de Análise Textual Discursiva (ATD), tendo com aporte teórico os estudos de Moraes e Galiazzi (2016). Segundo tais autores, a ATD pode ser compreendida como "um processo auto-organizado de construção de novos significados em relação a determinados fenômenos estudados, a partir de materiais textuais ${ }^{98}$ referentes a esses fenômenos" (MORAES e GALIAZZI, 2016, p. 67).

Os referidos autores apontam que a "auto-organização" se dá por meio de três processos de leituras dos materiais que compõem os textos do corpus da pesquisa, são estes processos: "a desconstrução dos textos do 'corpus', a unitarização; o estabelecimento de relação entre os elementos unitários, a categorização; o captar o novo emergente em que a nova compreensão é comunicada e validada" (MORAES e GALIAZZI, 2016, p. 34).

Ao seguir a organização proposta por Moraes e Galiazzi (2016) estabelecemos aproximações entre os materiais das entrevistas, nosso aporte teórico e nossas interpretações enquanto pesquisadores. Resultou disso a elaboração dos textos de resultados e discussões aqui apresentados

\section{O espaço lócus da pesquisa}

Tivemos como lócus de nossa pesquisa uma escola da rede municipal de ensino de Sobral, cidade do Estado do Ceará. De acordo com o Regimento Escolar (SOBRAL, 2014) da mesma, nela atende-se as etapas Educação Infantil e Ensinos Fundamentais Inicial e Final, nos turnos diurnos e EJA, no turno noturno.

\footnotetext{
${ }^{98}$ Moraes e Galiazzi (2016, p. 38) compreendem texto como "produções linguísticas, referentes a determinados fenômenos e originadas em um determinado tempo e contexto". Para nosso estudo, especificamos texto como sendo os materiais transcritos das entrevistas.
} 


\section{RevistAleph}

A referida escola é do tipo nucleada ${ }^{99}$, estando localizada na zona rural, mas sendo caracterizada, pela Secretaria Municipal de Educação (SEDUC-Sobral) e pelo Ministério da Educação (MEC), como de zona urbana. A sede funciona como escola-pólo, possuindo edifícios extensões em localidades da zona rural, que abrigam turmas de séries regulares e turmas de EJA. A Lei Municipal no 492/2004 (SOBRAL, 2004), em seu artigo 4으, torna facultativo a denominação destes edifícios, o que não isenta a escola-pólo dos apoios que ela deve conferir às turmas que ficam localizadas nas extensões, visa apenas reforçá-las como "partes integrantes e indissociáveis da unidade escolar autônoma" em que estão vinculadas (SOBRAL, 2004, p. 4).

A leitura da referida Lei nos permite compreender que a escola pesquisada é responsável por 5 turmas de EJA, estando estas em 4 localidades rurais diferentes. Todas estas turmas são do tipo multisseriadas, abrangendo, em uma mesma sala, estudantes do Primeiro e do Segundo Segmentos de EJA. A responsabilidade de cada turma fica a cargo de um único professor que, independente da área de sua formação, desenvolve a função de polivalente.

No que diz respeito aos aspectos estruturais, a Extensão Francisco Alves, onde localiza-se a turma EJA " $A$ " pesquisada, fica distante, aproximadamente, $1 \mathrm{~km}$ da escolapólo. Esta extensão compõe-se de: 3 salas de aula, 1 sala dos professores,1 sala de coordenação pedagógica, 1 cozinha, 1 depósito despensa, 1 depósito de materiais diversos e 4 banheiros. Uma destas salas de aula funcionava com uma turma de 60 ano, durante o dia e, à noite, com a turma EJA " $A$ ". Razão pela qual, quando de nosso acompanhamento, observamos já existir decoração com cartazes de boas vindas, de aniversariantes, entre outros. Contudo, percebemos que as salas possuem carteiras em tamanho adulto, quadro branco, birô escolar e são espaços ventilados ${ }^{100}$.

\section{Os estudantes da EJA}

Neste tópico trazemos o perfil da turma de EJA " $A$ " e dos estudantes entrevistados. Frisamos que, no ano de 2018, a escola pesquisada contou com o total de

\footnotetext{
99 Em Sobral, considera-se escola nucleada, aquela que atende classe de Educação Infantil, Fundamental Inicial e EJA do tipo multisseriada. Estas classes, em sua maioria, localizam-se na zona rural, enquanto que a escola-pólo, mesmo estando localizada na zona rural, é classificada como de zona urbana.

${ }^{100}$ Destacamos que, para a pesquisa em geral, também foram realizadas observações em algumas aulas na EJA. Estas ocorreram entre os meses de fevereiro e março de 2018. Neste artigo focamos apenas nas entrevistas realizadas.
} 


\section{RevistAleph}

536 estudantes regularmente matriculados. Desta quantidade, 131 correspondeu ao número de matrículas na EJA, que foram distribuídas em 5 turmas multisseriadas.

Acerca da turma EJA " $A$ ", esta contou com 24 estudantes matriculados. O perfil da referida turma está destacado na Tabela 1.

Tabela 1 - Perfil da turma de EJA "A"

\begin{tabular}{|c|c|c|c|c|c|c|c|c|c|}
\hline \multirow{2}{*}{ SEXO } & \multicolumn{4}{|c|}{ NÍVEL DE EJA } & \multirow[t]{2}{*}{ TOTAL } & \multicolumn{4}{|c|}{ FAIXA ETÁRIA } \\
\hline & I & II & III & IV & & $15-30$ & $31-45$ & $46-60$ & $61-75$ \\
\hline MULHER & 1 & 4 & 1 & 1 & 7 & 1 & 3 & 3 & 0 \\
\hline HOMEM & 3 & 1 & 4 & 9 & 17 & 4 & 5 & 7 & 1 \\
\hline TOTAL & 4 & 5 & 5 & 10 & 24 & 5 & 8 & 10 & 1 \\
\hline
\end{tabular}

Fonte: Dados codificados pelos pesquisadores.

Os dados da tabela acima nos permitem perceber uma predominância de estudantes homens na turma EJA "A". A maioria destes está no nível de EJA IV, isso quer dizer que, no ano de 2018, eles estariam concluindo o curso de EJA. A maioria destes possui entre 46 e 60 anos de idade. Já as estudantes mulheres, estas possuem idade acima de 31 anos e estão, a maioria, no nível de EJA II. Assim, percebemos que a turma EJA "A" é predominantemente masculina e de idade adulta.

Estes dados nos possibilitam compreender também que as mulheres, mesmo em menor quantidade, apresentam-se como estudantes na EJA da zona rural e estão, cada vez mais, ocupando os espaços noturnos de ensino. É possível que, o fato de elas estarem na EJA II e, portanto, atrasadas em relação aos homens de sua mesma idade, esteja ligado às suas condições econômicas, sociais e, principalmente, a condição de ser mulher em uma comunidade de zona rural.

Tendo como referência o diário de classe da EJA "A" de $2017^{101}$, utilizamos dos seguintes critérios para selecionar os informantes-chaves ${ }^{102}$ de nossa pesquisa: 1) menor quantidade de faltas durante o referido ano letivo e 2) não deveria, o estudante, estar matriculado na EJA IV. Este último critério foi assim estabelecido, pois, sendo o estudante do nível de EJA IV, era possível que ele não estivesse na escola no ano de 2018.

\footnotetext{
${ }^{101}$ Importante destacar que: por ser uma única turma multisseriada, ofertada em uma localidade rural, alguns dos estudantes da EJA "A" de 2018, formaram esta mesma turma em 2017; a seleção ocorreu em fevereiro de 2018, início deste ano letivo, por isso foi tomado o ano 2017 como base.

${ }^{102}$ Consideramos informantes-chave, os representantes de um grupo o qual pretendemos pesquisar (GIL, 2008).
} 


\section{RevistAleph}

Como nossos sujeitos entrevistados, definimos ser os estudantes mais presentes nas aulas da turma EJA "A". Seus perfis estão destacados no Quadro 1, que foi elaborado a partir do "Questionário da Amostra", do Censo Demográfico de 2010 (IBGE, 2010). Prezando pela suas identidades nos referimos aos mesmos com a simbologia "En", onde "E" representa a palavra "Estudante" e " $n$ ", representa um numeral, para diferenciá-los ao longo do texto.

Quadro 1 - Perfil dos estudantes entrevistados.

\begin{tabular}{|l|l|l|l|l|l|l|}
\hline ESTUDANTE & SEXO & IDADE & COR & $\begin{array}{l}\text { ESTADO } \\
\text { CIVIL }\end{array}$ & PROFISSÃo & $\begin{array}{l}\text { TEMPO } \\
\text { NA EJA }\end{array}$ \\
\hline E1 & F & 60 & Parda & Casada & Aposentada & 4 \\
\hline E2 & F & 55 & Preta & Solteira & Aposentada & 4 \\
\hline E3 & M & 50 & Parda & Casado & Pedreiro & 3 \\
\hline E4 & M & 30 & Preta & Solteiro & $\begin{array}{l}\text { Preparador } \\
\text { de pintura }\end{array}$ & 2 \\
\hline
\end{tabular}

Fonte: Dados codificados pelo pesquisador.

A partir da leitura das informações apresentadas no Quadro 1, compreendemos que os estudantes entrevistados apresentam características heterogêneas, o que é comum em turmas de EJA. Esta heterogeneidade, dada, sobretudo, pelas idades dos mesmos e de seus tempos de estudo na modalidade ${ }^{103}$, nos permite entender que cada um tem motivações específicas para nela permanecer.

Com exceção de E1, que morou um tempo na cidade, os demais estudantes informaram que sempre foram moradores da localidade rural onde a escola pesquisada situa-se. Todos eles informaram também que suas primeiras funções de trabalho foram em atividades ligadas à palha de carnaúba e na lavoura de milho, feijão, etc. As estudantes mulheres disseram complementar a renda de casa com a produção de chapéu de palha, enquanto que E3 informou ainda plantar roçado, mesmo trabalhando como pedreiro em obras na cidade. O estudante E4 trabalha somente com preparador de pintura em uma fábrica, também na cidade.

\footnotetext{
103 Todos os estudantes entrevistados informaram nunca terem abandonado a escola depois de passarem a estudar na EJA.
} 


\section{RevistAleph}

\section{Resultados e discussões}

Nesta seção trazemos os tópicos que compõem os resultados da pesquisa e as discussões sobre os mesmos. Tais resultados giram em torno de duas perguntas realizadas durante as entrevistas: (1) Como você se sente sendo estudante da EJA? e (2) O que motiva você a estar na sala de aula de EJA?

As respostas dos estudantes para a pergunta inicial nos permitiram compreender seus entendimentos e compreensões sobre a escola da zona rural. Já as respostas dos estudantes para a segunda pergunta, nos permitiram compreender e discutir os fatores de motivações que os levam estarem na escola e, desta maneira, os sentidos de suas permanências na EJA.

\section{Compreensões dos estudantes sobre a escola da zona rural}

Neste tópico destacamos que o roteiro da entrevista contou perguntas elaboradas a partir das temáticas abordadas em nossa pesquisa. Contudo, as perguntas iniciais tiveram o propósito de compreender quem são os estudantes da EJA, de que maneiras eles entendem os estudos no espaço escolar e as contribuições destes para suas vidas.

Depois de conhecer um pouco da história de vida de cada estudante e saber suas relações com a escola, perguntamos aos mesmos: (1) Como você se sente sendo estudante da EJA? Suas respostas trazem lembranças de seus tempos de estudos anteriores à EJA e demonstram suas compreensões sobre a escola da zona rural.

Para uma melhor análise das respostas dos estudantes sobre a pergunta (1), optamos por apresentá-las no Quadro 2. 


Quadro 2 - Como você se sente sendo estudante da EJA?
\begin{tabular}{|c|l|}
\hline ESTUDANTE & \multicolumn{1}{c|}{ RESPOSTA } \\
\hline \multirow{5}{*}{ E1 } & $\begin{array}{l}\text { Eu acho bom. Quando chega a hora eu vou pra escola, me empolgo. } \\
\text { Acho bom está estudando, a professora passando os dever, eu } \\
\text { renovando, aprendendo né. Por que no outro tempo a aula era } \\
\text { diferente de agora. Só ia pra frente depois que passava na cartilha. A } \\
\text { gente tinha bolo nas mãos quando não sabia. Tinha mais ignorância } \\
\text { na escola, botava a gente de castigo e agora na EJA não, os } \\
\text { professores ensinam bem direitinho. Agora eu tô achando melhor. }\end{array}$ \\
\hline E2 & $\begin{array}{l}\text { É bom. Maravilhoso. Tem diferença da EJA e da escola na casa da } \\
\text { Branca. É que eu aprendi mais agora na EJA que na escola da } \\
\text { Branca. Aprendi muita coisa, que eu não sabia quase nada. Nem os } \\
\text { números eu sabia fazer. Agora é bom. A professora faz atividade, ela } \\
\text { bota a gente faz. Eu gosto. }\end{array}$ \\
\hline E3 & $\begin{array}{l}\text { Ora eu acho bom. Bom, por que eu chego do trabalho de tarde, tomo } \\
\text { banho, aí chega a hora de ir pra escola, aí dá nove horas, termina. Eu } \\
\text { acho bom por que tô aprendendo mais alguma coisinha, uma soma } \\
\text { né. E eu gosto mesmo das aulas. }\end{array}$ \\
\hline E4 & $\begin{array}{l}\text { Agora eu tô gostando, como é que se diz, tá fazendo falta né pra } \\
\text { mim? Eu tenho que correr atrás do que eu perdi, deixei passar e } \\
\text { agora eu sinto melhora na minha vontade de ir pra escola. Tô } \\
\text { aprendendo alguma coisa, tipo os deveres. Quando eu tô no trabalho } \\
\text { dá cinco e meia eu já vou logo é me ajeitando pra eu vim pra casa, } \\
\text { pra eu tomar meu banho, me ajeitar e ir pra escola. }\end{array}$ \\
\hline
\end{tabular}

Fonte: Dados codificados pelos pesquisadores.

As respostas acima nos permitem a compreensão de que os sujeitos pesquisados demonstram um sentimento positivo em serem estudantes da EJA. O fato de estarem "aprendendo alguma coisa" (E4) é, possivelmente, um dos fatores que possibilita os mesmos se reconhecerem enquanto pessoas que frequentam uma escola e têm também uma vida escolar a ser contada.

As falas das estudantes mulheres trazem comparações entre a escola de EJA de "agora" (E2) e a escola de "outro tempo" (E1). Em uma primeira fala, antes de E1 nos responder a pergunta proposta, ela nos disse ter estudado "no grupo ginasial na cidade", o que nos permite compreender que o "outro tempo" por ela dito, refere-se às séries de turmas regulares da época em que estudou no ginásio. Já a estudante E2 estudou na "escola na casa da Branca". Esta "Branca", segundo E2 nos disse em fala anterior a destacada no Quadro 2, trata-se de uma "Senhora que ensinava as crianças que tinham família com condições de pagar os estudos naquela época".

Entendemos que as comparações feitas por E1 e E2, são apresentadas no sentido de mostrar que a escola atual, no caso, a EJA, representa um espaço "bom", diferente daquele por elas frequentados. A estudante E1, ao falar do "outro tempo", traz 


\section{RevistAleph}

lembranças de uma escola em que "Só ia pra frente depois que passava na cartilha", que empregava castigos físicos de "bolo nas mãos" àqueles que "não sabia".

Com E2, quando esta nos diz: "É que eu aprendi mais agora na EJA que na escola da Branca", percebemos que ela reconhece ter aprendido algo na "casa" em que estudou antes da EJA, mas, aprendeu "mais" nesta última. Para a referida sujeita, estar estudante da EJA "Agora é bom", pois tem a "professora" e "atividade". Entendemos que é esta atividade que possibilita E2 entender que na EJA ela aprendeu mais.

As falas de E1 e E2 também nos permitem analisar as possíveis práticas pedagógicas de seus professores da primeira escola e, agora, da EJA. Com E1, entendemos que o "castigo" era empregado pelos professores e isso a faz perceber que a escola de "outro tempo", "tinha mais ignorância". Possivelmente esta "ignorância" represente também às formas como os professores direcionavam suas aulas. Na EJA "os professores ensinam bem direitinho", o que faz E1 sentir-se bem, e achar "melhor" esta escola "de agora".

A fala de E2 demonstra que a prática pedagógica da professora da EJA centra-se em propor "atividades". Entendemos que estas atividades estejam relacionadas aos conteúdos escolares, com "os números", que a referida estudante diz agora ter aprendido.

Ao analisar estas falas, cabe-nos considerar queas estudantes E1 e E2, trazem histórias de vida e percursos escolares específicos. Além disso, suas vivências deram- se em tempos diferente, muito embora tenham idades aproximadas. Cabe-nos considerar também que a "diferença" (E2) entre as escolas se dá por que só recentemente, a partir da promulgação da Constituição de 1988 (BRASIL, 1988) e da LDB de 1996 (BRASIL, 1996), a Educação tornou-se, legalmente, um direito subjetivo de todos, e o ensino em “instituições próprias" (BRASIL, 1996, p. 8) tornou-se obrigatório. Assim, é sensato entendermos que, por trás dos sentidos e das compreensões das escolas "de agora" e de "outro tempo", existem questões históricas mais gerais e fatores políticos que precisam ser considerados.

Das falas dos estudantes homens, trazemos o "trabalho" como destaque. Suas falas permitem a compreensão de que a escola e o trabalho são seus espaços e momentos de ocupação: "eu chego do trabalho de tarde, tomo banho, ai chega a hora de ir pra escola” (E3), "Quando eu tô no trabalho dá cinco e meia eu já vou logo é me ajeitando pra 


\section{RevistAleph}

eu vim pra casa, pra eu tomar meu banho, me ajeitar e ir pra escola" (E4).Entendemos que, assim como as estudantes mulheres, os estudantes têm suas vivências específicas e diferenças de idades. Isto acaba implicando em suas compreensões sobre o sentido da escola e do trabalho para suas vidas. Além disso, temos que considerar suas condições de ser homem na zona rural.

Ambos os sujeitos homens trazem sentimentos positivos para o estar estudante da EJA. Contanto, E4 é enfático ao nos dizer que "Agora eu tô gostando, como é que se diz, tá fazendo falta né pra mim?". Esta fala de E4 é comum de ser ouvida entre estudantes da EJA, ela demonstra um sentido de culpa do sujeito por não ter aproveitado a "idade certa" (BRASIL, 1988, p. 121) em que ele deveria ter frequentando a escola.

Tal fala devota às limitações do estudante e acaba "[...] liberando as instituições e suas práticas, as sociedades, os modelos socioeconômicos e as (o)pressões culturais, chamando para si - e para uma condição irreversível - a responsabilidade para um provável fracasso nessa nova ou primeira empreitada escolar (FONSECA, 2012, p. 21, grifos da autora). Representa ainda, a escola como espaço onde se vai conseguir preencher o vazio de um tempo "perdido" que agora "tá fazendo falta" (E4).

Nas falas de todos os estudantes é notável as derivações do verbo "aprender". Percebemos que o "aprendendo" e o "aprendi" apresentados, vêm acompanhados de sentidos que entendemos estar ligados aos saberes escolares: "Aprendi muita coisa, que eu não sabia quase nada. Nem os números eu sabia fazer" (E2), "tô aprendendo mais alguma coisinha, uma soma né" (E3); ou ainda, às atividades escolares, entendidas aqui como os "dever": "a professora passando os dever, eu renovando, aprendendo né" (E1), "Tô aprendendo alguma coisa, tipo os deveres" (E4).

Estas interpretações nos permitem a compreensão de um sentido de escola como “instituição própria de ensino" (BRASIL, 1996, p. 8), como espaço onde se vai aprender os saberes dos conteúdos escolares. Tais saberes ainda tão cobrados em uma sociedade e sistemas de "educação" que se limitam a compreender aprendizagem como algo que pode ser mensurado, sobretudo, pelo "progresso acadêmico em um número restrito de áreas curriculares especialmente Língua, Ciências e Matemática" (BIESTA, 2012, p. 814).

Ao mesmo tempo, entendemos que os estudantes compreendem a escola como um espaço "bom. Maravilhoso" (E2), em que, ao aprender os conteúdos escolares, estarão eles no caminho para conseguir atingir seus objetivos. Nos dizeres de Canário 


\section{RevistAleph}

(2008, p. 74), seria uma escola do "tempo de 'promessas'", quais sejam estas: "uma promessa de desenvolvimento, uma promessa de mobilidade social e uma promessa de igualdade" (CANÁRIO, 2008, p. 74, grifos do autor).

Entendemos que o fato de os sujeitos estarem "aprendendo", além de representar seus sentimentos de ser estudantes, sinalizam para algumas possíveis motivações de suas permanências na escola, questões do tópico posterior.

\section{Sentidos das permanências dos estudantes na EJA}

No tópico anterior, ao analisar as compreensões dos estudantes sobre a escola da zona rural, percebemos que há algo, para além do "aprender", que os fazem buscar a EJA. Este "aprender", por todos citados, veio carregado dos conteúdos escolares, das atividades, mas também de uma perspectiva positiva dos sujeitos sobre estarem estudantes da EJA.

Neste tópico apresentamos as motivações dos estudantes buscarem à EJA. As falas dos mesmos nos permitiram compreender os sentidos de suas permanências na escola, que foram captados a partir da seguinte pergunta: (2) O que motiva você a estar na sala de aula de EJA? As respostas dos mesmos estão destacadas no Quadro 3.

Quadro 3 - $O$ que motiva você a estar na sala de aula de EJA?

\begin{tabular}{|c|l|}
\hline ESTUDANTE & \multicolumn{1}{c|}{ RESPOSTA } \\
\hline E1 & $\begin{array}{l}\text { A professora né. Ela foi lá em casa, me pediu pra eu vir ai eu vim. Eu } \\
\text { nem vinha mais sabe. Ela foi lá em casa, falou como ia ser as aulas e } \\
\text { eu tô aqui. Tô gostando muito do aprendizado né. E do ensino dela } \\
\text { também. Tem as atividades, as prosa na hora da aula, tem as menina } \\
\text { da rua aqui, aí a gente estuda e proseia. Aqui eu me sinto em casa. }\end{array}$ \\
\hline E2 & $\begin{array}{l}\text { É que eu quero aprender né. A gente vai lá, a professora ensina. Tem } \\
\text { as conversação também. A gente fica entretido. Eu gosto da } \\
\text { professora, mas gosto mais do ensino dela. }\end{array}$ \\
\hline E3 & $\begin{array}{l}\text { É por causa que eu quero aprender mais um bocadinho que eu não } \\
\text { sei. Os meninos, o A, o B, lá me ajudam e a professora também. E pra } \\
\text { saber chegar na parte saber ler. E a minha vontade também é } \\
\text { comprar minha moto um dia e tirar minha habilitação, tá } \\
\text { entendendo? Por que disso tudo eu preciso, e vai me ajudar a ir de } \\
\text { casa, pro trabalho e pra escola. }\end{array}$ \\
\hline E4 & $\begin{array}{l}\text { O que me motiva é que eu quero um trabalho melhor. Quero mudar } \\
\text { de profissão, que essa que eu tenho tá causando mal. E isso só vai se } \\
\text { a pessoa estudar. E eu nem tenho mais preguiça de ir para escola } \\
\text { não. A escola é calma, a sala de aula é boa, a gente fica tranquilo, } \\
\text { escuta bem diretinho o que a professora fala, tem os colegas que } \\
\text { ajudam também. }\end{array}$ \\
\hline
\end{tabular}

Fonte: Dados codificados pelos pesquisadores. 


\section{RevistAleph}

Nas falas acima percebemos, mais uma vez, a presença do verbo "aprender". Estas falas nos permitem reafirmar que o "aprender" está ligado aos conteúdos escolares, referido aqui como "ensino". A resposta de E2 explicita esta nossa interpretação: "É que eu quero aprender né. A gente vai lá, a professora ensina". Nos informa Cipiniuk (2017), ser possível que a vontade, o desejo de aprender dos estudantes da EJA seja mobilizado antes mesmo de eles afiliarem-se à unidade de ensino, sendo o seu "estar" na escola movido, dentre outros fatores, pelo "aprendizado da leitura e da escrita" (CIPINIUK, 2007, p. 89) e, complementamos, com a aprendizagem das "contas" de uma "matemática escolar" (FONSECA, 2012, p. 28).

Ao citar a "professora", compreendemos que E2 refere-se à prática pedagógica da mesma, no modo como a docente ensina. Esta nossa compreensão pode ser percebida no complemento da resposta da referida estudante: "Eu gosto da professora, mas gosto mais do ensino dela". Ou seja, há um sentimento de E2 para com sua professora que, somado à forma com que a docente leciona, desperta o gosto pelo "ensino" desta.

A figura da "professora" também aparece na resposta de E1, mas na forma de incentivadora direta de a estudante voltar à EJA: "A professora né. Ela foi lá em casa, me pediu pra eu vim aí eu vim". Contanto, a maneira como a docente desenvolve sua prática pedagógica nas aulas da EJA contribui para E1 continuar na escola, nos diz esta, referindose à sua professora: "Tô gostando muito do aprendizado né. E do ensino dela também".

Os estudantes homens, além do "aprender", apontam estarem na EJA motivados pelo desejo de realizações futuras: "E a minha vontade também é comprar minha moto um dia e tirar minha habilitação, tá entendendo?" (E3), "O que me motiva é que eu quero um trabalho melhor. Quero mudar de profissão, que essa que eu tenho tá causando mal" (E4). É mister reafirmar que estes estudantes se encontram na condição de trabalhadores, para compreendermos que o "aprender mais um bocadinho" e "tirar a habilitação" é o "disso tudo" que E3 precisa para melhorar sua vida. Assim como, compreender que, para E4 mudar de profissão "só vai se estudar".

Estas falas de E3 e E4 nos permitem entender que o fator "trabalho" também possibilita a permanência dos estudantes na EJA, em detrimento de pesquisas que o têm apenas como fator de evasão (CARMO, 2010). Ao analisar os enigmas da evasão de jovens e adultos da escola, Carmo (2010) nos informa: 


\section{RevistAleph}

[...] o "trabalho" é a resposta mais presente no senso comum e, igualmente em várias pesquisas acadêmicas e institucionais. No entanto, essa resposta não satisfaz embora empiricamente observável. O corolário dela é que o trabalho como causa principal da evasão na EJA retifica-se, substancializa-se, coisifica-se (CARMO, 2010, p. 32, grifo do autor).

O autor chama atenção para a forma com que o "trabalho" é tido e discutido como razão da evasão dos estudantes da EJA. O uso dos termos "retifica-se" e "coisificase" demonstra a crítica de Carmo (2010) para a aceitação que seja natural um jovem ou adulto, inseridos em uma sociedade capitalista desigual, procure um "trabalho" que exige de sua força barata, em detrimento de uma escolarização, que lhe é direito. No que diz respeito às pesquisas acadêmicas, a aceitação natural dá-se por meio do silenciamento de discussões mais aprofundadas, o que fica entendido ser o "trabalho" a razão única, mais reinante, que encaminham os estudantes para evadirem-se da escola.

Além da busca pelo aprendizado dos conteúdos escolares e de realizações futuras, as falas dos quatro estudantes nos possibilitam compreender existir boas relações de amizades, de afetividade positiva entre seus pares na sala de aula. Percebemos estas relações a partir das seguintes falas: "Tem as atividades, as prosa na hora da aula, tem as menina da rua aqui, ai a gente estuda e proseia. Aqui eu me sinto em casa" (E1), "Tem as conversação também. A gente fica entretido" (E2), "Os meninos, o $A$, o $B$, lá me ajudam e a professora também" (E3) e "tem os colegas que ajudam também" (E4). Estas ajudas dos colegas, as "conversação" e "as prosa", certamente tornam o ambiente escolar mais receptivo para os jovens e adultos. Entendemos que estas relações de afetividade se compõem como táticas de sobrevivência e de permanência dos estudantes na EJA (MILETO, 2009).

Tendo como referência o período dos estudantes na EJA e a busca pelos saberes escolares, entendemos um sentido de suas permanências na escola como "ato de durar no tempo, que possibilita não só a constância do indivíduo, como também a possibilidade de transformação e existência" (REIS, 2016, p. 74). Compreendemos em Reis (2016) que o "durar no tempo" refere-se ao prazo de conclusão de um curso, de permanente "constância", estada no espaço escolar, por exemplo; o que, de acordo com a autora, está diretamente relacionado à trajetória que o estudante desenvolverá ao longo de sua vida 


\section{RevistAleph}

escolar e, "depende, sobretudo, das condições para efetivação dessa trajetória" (REIS, 2016, p. 75).

Considerando as relações de afetividade entre os sujeitos com seus pares, bem como, os sentimentos dos mesmos de estarem estudantes na EJA, compreendemos um sentido de permanência ligada ao pertencimento dos jovens e adultos à escola. Segundo Fávero (2016) analisado por Carmo e Silva (2016), este pertencimento liga-se ao fato de que os estudantes mais adultos e, principalmente, os idosos, "voltam à escola porque a escola fez falta na vida deles" (CARMO e SILVA, 2016, p. 61) e, por isso, muitas vezes, nela permanecem.

De um modo geral, entendemos que os estudantes de EJA têm razões e motivações para estar na escola que Ihes são específicos quanto à sua condição humana de ser mulher, homem, trabalhadores ou não, moradores da zona rural e seus desejos de realização pessoal. Pode-se dizer que há um ponto que os tornam comum: o fato de estar no espaço de educação escolar aprendendo, Ihes permite enxergar uma transformação em suas vidas futuras.

\section{Considerações finais}

Este artigo buscou apresentar os sentidos das permanências de estudantes na EJA, que foram percebidos a partir de entrevistas realizadas com jovens e adultos de uma escola municipal localizada zona rural do Ceará.

Tivemos quatro estudantes como sujeitos entrevistados, sendo duas mulheres e dois homens, todos de uma mesma turma multisseriada. As respostas das estudantes mulheres trazem lembranças dos espaços escolares por elas frequentados antes da EJA. Suas motivações para estar na escola zona rural estão ligadas ao desejo de "aprender", mas também pela influência da "professora" e de suas formas de "ensinar".

Nas falas dos estudantes homens, percebemos suas motivações relacionadas à busca por "aprender" os saberes escolares e também às conquistas futuras, seja de "tirar a habilitação", para melhorar na locomoção entre casa, o trabalho e a escola, ou a de conseguir um "trabalho melhor". As respostas de ambos os estudantes nos sinalizam o fator "trabalho" (E4) como potencial influenciador de suas permanências na escola. 


\section{RevistAleph}

Em linhas gerais, as respostas dos sujeitos apontam nossos entendimentos para a compreensão de dois sentidos de suas permanências na escola: um primeiro, ligado ao ato de "durar no tempo", de estar constantemente presente no espaço escolar. Podemos compreender que esta permanência se dá pela busca de "aprender" os saberes escolares, os quais os estudantes entendem contribuir para suas conquistas. E um segundo sentido, que entendemos estar ligado ao sentimento de "pertencimento" dos estudantes à escola e à turma de EJA.

Encaminhamos nossas considerações finais, destacando que as motivações e os sentidos de permanências apresentados em nossa pesquisa, dizem respeito a um público de estudantes que têm realidades e estão em um espaço específicos. Com tanto, as falas apresentadas mostram suas compreensões sobre a escola, professores e algumas práticas pedagógicas direcionadas ao ensino na EJA, permitindo-nos tecer reflexões sobre as políticas de educação voltadas para jovens e adultos.

\section{Referências}

BRASIL. Constituição Federal da República Federativa do Brasil. Senado Federal. 25 ed. Brasília, DF, 1988. Disponível em <https://www2.senado.leg.br/bdsf/bitstream/handle/id/518231/CF88 Livro EC91 2016.pdf> Acesso em: 30 mai. 2017.

BRASIL. Lei no 9394 de 20 de dezembro de 1996. Aprova a Lei de Diretrizes e Bases da Educação Nacional. Conselho Nacional de Educação/ Câmara de Educação Básica. Brasília, 1996. Disponível em

<http://www2.senado.leg.br/bdsf/bitstream/handle/id/529732/lei de diretrizes e bases 1ed.pd f> Acesso em: 30 de mai. 2017.

BIESTA, G. Boa educação na era da mensuração. trad. Teresa Dias Carneiro. Cadernos de Pesquisa, Fundação Carlos Chagas, v. 442, n. 147, p. 808-825, 2012.

CANÁRIO, R. A escola: das "promessas" às "incertezas". Educação Unisinos, v. 12, n. 2, p. 73-81, 2008.

CARMO, G. T.O enigma da educação de jovens e adultos: um estudo das evasões e retorno à escola sob a perspectiva da teoria do reconhecimento social, 2010. 339f. Tese (Doutorado em Sociologia Política) - Universidade Estadual do Norte Fluminense Darcy Ribeiro, Campo dos Goytacazes, 2010.

CARMO, G. T.; CARMO, C. T. A permanência escolar na Educação de Jovens e Adultos: proposta de categorização discursiva a partir das pesquisas de 1998 a 2012 no Brasil. Arquivos Analíticos de Políticas Educativas, v. 22, n.63. Dossiê Educação de Jovens e Adultos II, 2014. Editoras convidadas: Sandra Regina Sales \& Jane Paiva. 


\section{RevistAleph}

CARMO, G. T.; SILVA, C. B. Da evasão/fracasso escola como objeto sociomediático à permanência como objeto de pesquisa: o anúncio de uma construção coletiva. In: CARMO, G. T. (org.). Sentido da permanência na educação de jovens e adultos: anúncio de uma construção coletiva. Rio de Janeiro: Tempo Brasileiro, 2016, p.41 -72.

CHIZZOTTI, A. Pesquisa qualitativa em ciências humanas e sociais. 5. ed. Petrópolis: Vozes, 2013.

CIPINIUK, T. A. Analfabeto: problema social e desonra pessoal. Niterói: Eduff, 2017.

FONSECA, M. C. F. R. Educação matemática de jovens e adultos: especificidades, desafios e contribuições. 3 ed. Belo Horizonte: Autêntica, 2012.

GIL, A. C. Métodos e técnicas de pesquisa social. 6. ed. São Paulo: Atlas, 2008.

IBGE, Instituto Brasileiro de Geografia e Estatística. Questionário da Amostra. 2010. Disponível em $<$ https://censo2010.ibge.gov.br/images/pdf/censo2010/questionarios/questionario amostra cd2 010.pdf> Acesso em: 17 mai. 2017.

LÜDKE, M.; ANDRÉ, M. E. D. A. Pesquisa em educação: abordagens qualitativas. 10 reimpr. São Paulo: EPU, 2007.

MILETO, L. F. M. No mesmo barco, dando força, um ajuda o outro a não desistir: estratégias e trajetórias de permanência na Educação de Jovens e Adultos, 2009. 215 f. Dissertação (Mestrado em Educação) - Universidade Federal Fluminense, Niterói, 2009.

MORAES, R.; GALIAZZI, M. C. Análise Textual Discursiva. 3 ed. rev. ampl. Ijuí: Unijuí, 2016.

OLIVEIRA, Marta Kohl de. Jovens e adultos como sujeitos de conhecimento e aprendizagem.

Revista Bras. Educ. n. 12. São Paulo: Anped, Associação Nacional de Pesquisa e Pós-graduação em Educação, p. 59-73, 1999.

REIS, D. B. O significado de permanência: explorando possibilidades a partir de Kant. In: CARMO, G. T. do (org.). Sentido da permanência na educação de jovens e adultos: anúncio de uma construção coletiva. Rio de Janeiro: Tempo Brasileiro. 2016, p. 73-92

SOBRAL. Lei no 492 de 06 de janeiro de 2004. Dispõe sobre a Nucleação das Escolas da Rede Municipal de Ensino, e dá outras providências. Câmara Municipal de Sobral. 2004. Disponível em $<$ https://www.camarasobral.ce.gov.br/painel/files/docs/norma lei/LO4922004200401060001pdf 22062015085728.pdf> Acesso em: 06 de junho de 2017.

SOBRAL. Regimento Escolar. Escola de Educação Infantil e Ensino Fundamental José Arimateia Alves. 2014.

Data de envio: $24 / 09 / 2019$

Data de aceite: 18/06/2019 